IRA-International Journal of Applied

Sciences

ISSN 2455-4499; Vol.04, Issue 02 (2016)

Institute of Research Advances

Pg. no. 351-357

http://research-advances.org/index.php/IRAJAS

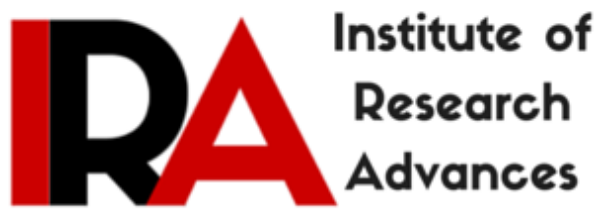

\title{
Impact of Military Actions on Sustainable Development in Iraq
}

\section{Ibraheem M . Aliyas}

Northern Technical University, Technical Institute of Mosul, Iraq.

Type of Review: Peer reviewed.

DOI: $\underline{\text { http://dx.doi.org/10.21013/jas.v4.n2.p16 }}$

\section{How to cite this paper:}

Aliyas, I. (2016). Impact of Military Actions on Sustainable Development in Iraq. IRAInternational Journal of Applied Sciences (ISSN 2455-4499), 4(2), 351-357. doi:http://dx.doi.org/10.21013/jas.v4.n2.p16

(C) Institute of Research Advances

\section{$(\mathrm{oc})$ EY-NC}

This works is licensed under a Creative Commons Attribution-Non Commercial 4.0

International License subject to proper citation to the publication source of the work.

Disclaimer: The scholarly papers as reviewed and published by the Institute of Research Advances (IRA) are the views and opinions of their respective authors and are not the views or opinions of the IRA. The IRA disclaims of any harm or loss caused due to the published content to any party. 


\section{ABSTRACT}

The military actions in Iraq most challenge influenced to each life types especially on sustainable development which representing by environment such as (biosphere; soil, water resources \& air), social and economic, spawned the negatively traces for all sectors of sustainable development, in particular including: murder, destruction of infrastructure, agricultural production, biodiversity, industrial production, education, health, and others. Where occurred three wars; 1980, 1991 and 2003. Until now Iraq suffers from their impacts, where protection of sustainable development could be strategic necessity today's. Human who lives above the Earth is main reason in impact on the environment whether by the reason war or Irrationally use of natural resources which produce; pollution, smoke, waste, and epidemics.There is no doubt that the environment is a natural habitat for all human activities so events current on the earth surface, therefore unaffected and affect them, just the human living in healthy lives atmosphere where causes of varying degrees from effects on the environment. Our research is trying to find out how the in fact that environmental pollution by the reason of war hampering sustainable development and threatening the lives of Population, in order to reach this goal, included this research; sociological, environmental,ecnomic security for the people of Iraq. caused unrest killed more than 85,000 civilians in 2007, estimated the number of refugees 4.7 million (about 16\% of Iraq's population) in April 2008, and two million Iraqis have fled to neighboring countries, they are now according to the International Red Cross and the statements in the humanitarian situation bad, as the number of people killed during the war were 1.3 million people and in the month of August 2008 Iraq took fifth in unstable countries index.

Keywords: Military actions, Sustainable development, Challenges, Environment, Iraq.

\section{Research importance}

Explain the importance of this study from assess the effect of military actions on sustainable development and other productivity sectors in negative form such as; how to get rid of its harmful as pollution radiation, stripping the land from their vegetation cover, soil degradation, water and air pollution, the methods of getting rid of the explosives and the Bridging the trenches, holes, remove the effects of the remaining military equipment, how to rehabilitate the infrastructure of the country then re-life of the sites productivity and how to protect neighborhoods from their effects.

\section{Research objects}

Recognize the reality of the Iraqi environment and the most important challenges that passed detection efforts the problems of the Iraqi environment the reality of the environment on the fields of; ecological, social and economic development, especially the field of Health and productivity sectors, which is a determining factor in the life of the population.

\section{Research Methodology}

Find adopted two approaches to achieve the most accurate results, inductive and analytical approach.

\section{Introduction}

Iraq is located in southwest Asia, one of the Middle East countries constitute the northeastern part of the Arab nation extends between latitudes $\left(29^{\circ} 5,37^{\circ} 22^{\circ}\right)$ north and between longitudes $\left(48^{\circ} 45^{\circ}, 38^{\circ} 45^{\circ}\right)$ east. Iraqi area occupies 44 million Hectare. Where 15 governorates suffer from military actions impacts from total the 18[1]. Iraq in past had the 
economical ingredients; petrol and natural gas, mineral resources such as, sulfur phosphorus and silicon, water resources, fertile land, human resources, scientific skills, investments and fit environment, that these qualifications made Iraq a prosperous country and a strong economy. But the war prevented to achievement of development comprehensive, especially the wars of 1991 and 2003 where the infrastructure will be destroyed of the country then weighed on Sustainable Development, where damage included all walks of life, including environmental factors as: environmental pollution and radiation on the biosphere including; acid rain, soil degradation due to the detonation gases, the level of the dust storms have increased because of military vehicles by $54 \%$, expanded the scope of desertification by $92 \%$, deteriorated of ecosystems such as; aquatic complexes, Stripping the land from vegetation over, degradation of natural reserves and biodiversity, increased the logging by a lack of fuel, abounded fires because of the bombing, loss the habitat, meadows, landscapes, pastures, oases, basins of fishes .Occurred all the spectrum by the reason of military operations which caused ecological pollution and desertification and land filled by sands [2]. on the economic level: hit the growth and development of economic by stagnation and failures which represented by; increased of unemployment, low of field labor, low productivity of all sectors, low per capita and national income level [3]. As in the social aspect; hit the community of murder because of bombing, get disability for people, displacement and emigration about 4-5 million people, rising of illiteracy proportion, weak purchasing power due to high prices, health degradation because of the low level of living, loss of civilization case in food, clothing and drink, construction and transportation, get an disturbance in the balance between food security and population growth], finally; delayed Iraq of progress and achieve sustainable development.

\section{Results and Discussion}

Environmental safety consider one of the most important elements for organisms life sustainability which contributes to people's ability to the practice of various activities the pollution is one of the main challenges facing the environment where reflecting theirs shadow on the population. From the dangerous effects on the biosphere and living organisms is pollution due to wars where reflected on sustainable development. The environment is a natural habitat for all human activities also for current events on the planet surface, affected by these activities and effect on them, just that human living by healthy life in a civilized atmosphere were causing varying degrees of impact on environment where must commensurate with the degree of civilization and urbanization progress in that society, as befell in Iraq for more than three decades by absence of environmental security for the Iraqi people by the reason of military actions. Refers the Environment Program of the United Nations (UNFP) the destroyed of environment is one of the inevitable results that correlative the wars [4]. For environmental pollution there is multiple forms necessary for researcher to recognize them to estimate the size of the damage which caused to the environment, so we will try through this research to identify the most important those forms, one forms of pollution is radiation spread and radioactive ammunition although the passage of time to stop the last war, still the radioactive munitions spread throughout Iraq. The contamination from depleted Uranium (DU) and other military-related pollution is strongly suspected causing a sharp rise in congenital birth defects and cancer cases in Iraq ,the figure (1)explain death situation from 2001-2011 in several causes which the cancer takes high percentage [5] and makes the country unlivable. Low water in rivers has spelt disaster of water rendering it unfit for human and animal consumption. Water supply from Euphrates and Tigris has dramatically dwindled, affecting Iraq's fertile agricultural lands and the underground water supplies that have depleted with no signs of recovery. Consequently, drought has become a national issue ,because of the bombing happened defect in the sewer systems [6,7] Soil pollution one of the main forms of environmental pollution in Iraq, the Iraqi soil on the face particular one of the biggest challenges for the future strategies of the Iraqi state on levels economic, health, despite the fact that Iraq until the end of the seventies he owned one of the cleanest 
environments in the world, but that after the wars that made the soil become a target vandalized because of mass destruction and the accumulation of various toxic waste that threatens the environmental security by reason of the mass destruction that threaten the continuation different forms of life and therefore requires us to quickly and conducting studies and field measurements for different soil contaminants. Exposed soils in Iraq to a number of influences and to varying degrees, soil salinization and erosion of the most prominent factors that affect the vital activity can be highlights summarized Where the bombing of the war caused the impact on petrol installations during the war in 1991 by bombing of four large oil refineries, Shuaiba, Nasiriyah, Aldorrah and Baiji, which lies within the largest cities were the main production projects and large storage warehouses were destroyed in the Rumaila and Zubair fields and production facilities and filtering in Kirkuk as well as pumping stations, transmission lines and warehouses of petrol products and this led to pollution by oil derivatives through leakage or the combustion of large amounts of oil and its derivatives, , estimate amounts crude oil that burned or leaked to the neighboring land and surface water up 11173000 barrels, also have pollution reached land neighboring, the burning of oil wells by aerial bombardment in the fields causes lands corrupted in southern Rumania and oil installations in Kirkuk to $7 \mathrm{~km}$ agricultural area estimated at 1613 hectares and the loss of crop production of tomato and barley in agricultural lands which contain $20 \%$ oil, in addition to burning sulfur project in Mishraq located in Nineveh province which caused the combustion of large agricultural areas and the destruction of soil by sulfur poisoning [8]. As well as depleted Uranium, which used in the last Gulf War, the most dangerous sources of environmental pollution and soil in Iraq the which raised the negative effect and dangerous to human health and the suffering of cancer and malformations disease congenital diseases and infertility for men, women and others as well as the presence of depleted Uranium dust in soil is estimated 2000 tons according to Pentagon estimates, the Committee of UN for Environment. The pollution are stationed in areas of Baghdad, Southern areas where military operations that broke and we know that these areas Intertwined with residential and agricultural areas, and this will have a very complicated due to the contamination in the soil because along the wind moves and water and rain movement that led to the spread of depleted uranium dust to earth surface. As air pollution is the most dangerous and the most prominent forms of pollution in Iraq, the qualitative study were ambient air one of the fundamental study in environmental situation in Iraq, although the most important indicators sources air pollution in Iraq were summed up natural resources which takes the first two forms falling dust, which is one of the indicators certified ambient air quality at the provincial level, especially the neighboring areas where desert regions has indicated technical studies and reports conducted over the past years to the airborne dust is a major problem, followed by the rising dust and dust storms which familiar phenomena of nature in Iraq and has become a repetitive occurrence markedly over the last decade because of the removal of vegetation cover and stopping sand dune stabilization, particularly in the southern regions projects from Iraq in addition to the effects of drought during the recent period the second form is the suspension particles (SP), noted the environmental studies conducted in Iraq in this area that the concentrations (SP) is characterized by a rise on the global determinants and volatility according to the data available on those years, and the available data indicate that concentrations of these particles rate during the year 1990 up to the limits $139 \mathrm{Microg} / \mathrm{m} 2$, ranging from 1249 Micro $\mathrm{g} / \mathrm{m} 2$ during the year 1991, indicated these concentration levels ranging from 38800 micro g / m2 to $3145 \mathrm{Micro} / \mathrm{m} 2$ during the 1997 year. The water pollution another facet of pollution which suffers the Iraqi environment where the sector of potable water supply for drinking special interest within the strategies and development plans In Iraq as of directly affecting the health and welfare of the community it has paid attention to development plans clear to provide drinking water in urban and rural areas. As for the quality of Iraq's water and environmental survey refers to Iraq Report 2005 that the water of Iraq in general form unfit ofor consumption by a proportion $60 \%$, that rural population enjoy by potable drinking water 33\%, compared with $60 \%$ in urban areas [9].From the results of the recent war increased damage sustained by the water delivery and sanitation systems, resulting 
in high levels of pollution health hazards and interruption of frequent power supply causing the stoppage of work pumps that remove waste products and the distribution of water, causing a flood of farms and polluted by salt also the fumes emitted from the territory of the fires ignite the oil wells and oil trenches added more pollution to air, soil and the degradation of the ecosystem because of heavy shelling and the movement of a large number of vehicles and troops[10] Environmental pollution on the fields of social, It could be limited to the most important developmental areas that were most affected by environmental pollution where of health sector medical studies on members of the armed forces and civilians have been conducted and were results as follow with respect to the military involved in the theater of operations have been conducted and descriptive clinical injuries cancer on a sample of individuals ranging from 1972-1941 age ,study shown their new born an increase in injuries of various cancer so lymph glands which injuries and cancer blood was higher than the rest of the injuries, the chemical toxicity of Uranium when penetrate the target of not less dangerous from the radiological effects of this weapon on human health. have been

those who are residents of areas that delayed growth of studies prepared in this regard showed children who are 6 years old, Increase in the number of genetic diseases associated with changes in such as chromosomes eye disease genetic and genetic syndromes such as Mongolian child and an increase in the number of members in the body natural change in the size, shape and location the effects of radioactive contamination on the demographic reality in Iraq It reflected the deterioration factors in the health sector due to the weak performance potential and the resulting economic blockade cumulatively over the years beyond 1990, and increased complexity health conditions later effects left by the impact of excessive and irresponsible use of Uranium depleted, which infected 7500 person annually[11,12], receives Institute Medicine and Atomic Radiation in Baghdad of 150 infected per day of all Iraqi provinces, estimates foreign researchers that the incidence of cancer caused by depleted Uranium in the total population in Basra 12\% which is equal 30000 citizen.Possibible summarize the impact of military actions in Iraq on environment level because of pollution which infected all life components; where thrown 84 thousand of bombs, 25 million mines which caused gases emission of $\mathrm{SO}_{2}$, fragments of the bombing reached 6,370 thousand ton, increased dust and sand storms by $80 \%$. In economic side lowest of gross domestic product, Importation increased to $85 \%$, reduction the agricultural production to $70 \%$, lowest animal production to $90 \%$, fish mortality, extinction of biodiversity to $65 \%$,forest removing reach $0,2 \%$ annually, degradation of Date Palms by average $66 \%$,from 30 million to 9,5 million Palms, reduction water resources $45 \%$, increased desertification to $92 \%[13,14]$.all these factors has affected on sustainable development in Iraq. 


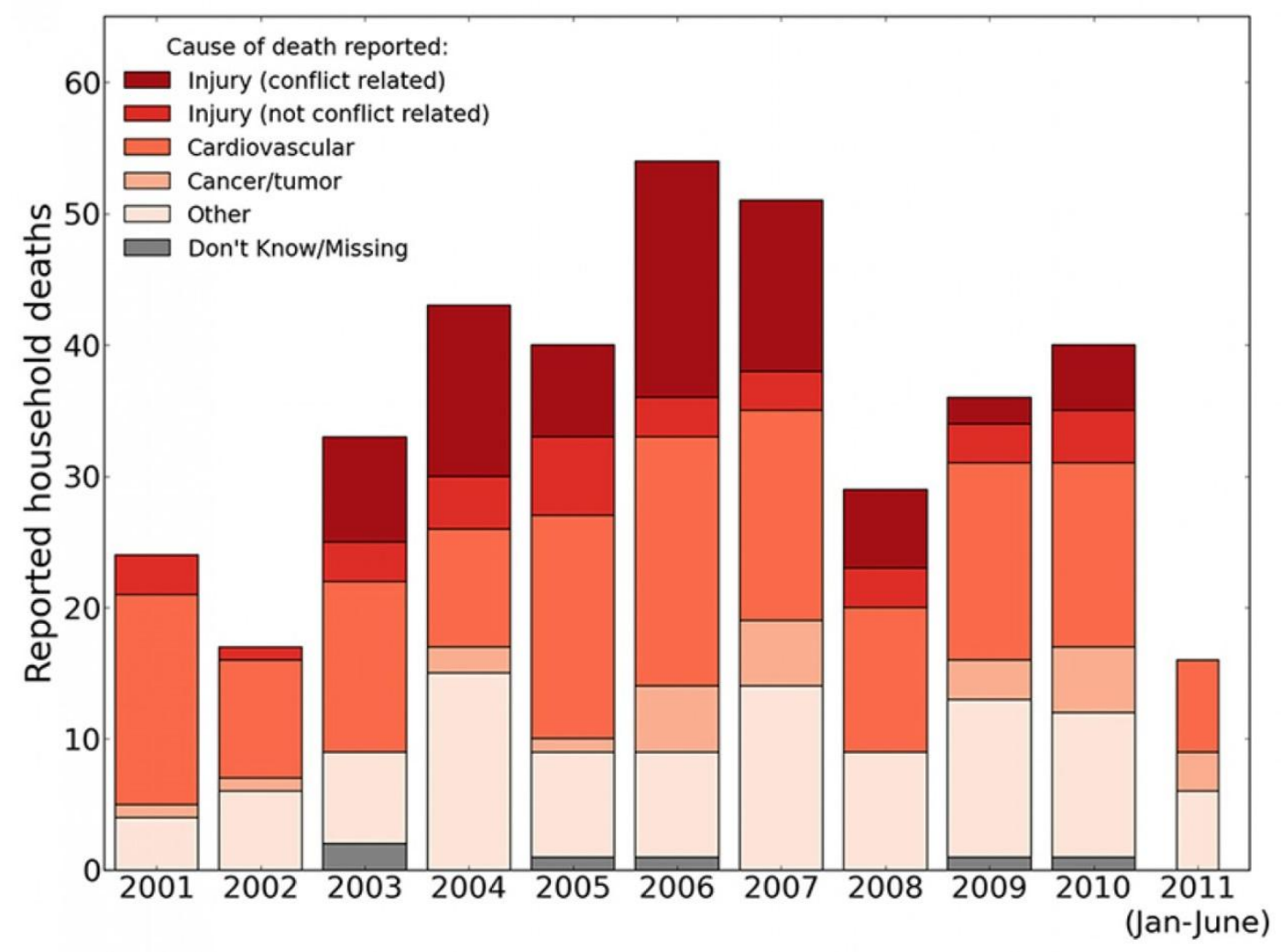

Figure (1) Explain cause of death in Iraq by the reason of military actions

\section{References}

1- Waleed I. AL-Rijabo; Hanee M.Salih, (2013), Spatial and Temporal Variation of Rainfall in IRAQ, ISSN: 2278-4861. Volume 5, Issue 4(Nov. - Dec. 2013), PP. 01-07.

2-A.S.Hadel, Mustak T.Jabbar, (2010), Application of remote sensing and GIS in the study of environmental sensitivity to desertification (2010) -2; pp. 101- 112 .

3-S.G.Thomas, (1997), Science and Desertification Debate, journal of Arid Environonmet.(1997) -37:P.599-608.

4- Abdullah, Abdul Khaliq. (1998). Sustainable development and the relationship between environmental development. Studies In development, the Center for Arab Unity Studies. Beirut. P.243.

5-Sharif, Dalia. (1991). Report of the United Nations reduced to a horrific life expectancy between Iraqis, Baghdad. Number -10: (363).

6-Frankie, Rend Rahim. (2003). Democratic control in Iraq. Report No. 1 on the situation in Iraq. Arab Future Magazine Issue -68: (297).

7-Alkovaoa, Haidar. (2001). Environmental disaster in Iraq. Arab affairs magazine. Issue (4); 42.

8- Muthanna Abdul Razzaq. (2001). Analytical look at the environmental effects of the Iraq, House of Wisdom magazine, Baghdad. 219. 
9- The Iraqi Ministry of the Environment. (2005). Environmental scanning in Iraq in 2005. Baghdad. 4.

10- United Nations of Environment Programme. (1995). Arabs and the environment, a special bulletin on the occasion of anniversary Sixty-sixth of the United Nations, New York. Number 15 .

11. Mackie, Azzam. (1991), The use of depleted uranium in the Gulf War. New Culture Magazine, Baghdad, May 22.Number (288).

12. Environmental Ministry. (2004). Proceedings of a symposium of radioactive contamination in Iraq, July. 20. Baghdad.

13- Salim Mattar, (2010), the Encyclopedia of the Iraqi environment (disasters and environmental problems the Iraqi, No; 1, Page 246.

14- Ahmed Abrihi, (2011), The Iraqi economy and the prospects for the future, a scientific article, Mesopotamia journal, page 1-11. 